\title{
A Novel Glycoprotein of Feline Infectious Peritonitis Coronavirus Contains a KDEL-Like Endoplasmic Reticulum Retention Signal
}

\author{
H. VENNEMA, * L. HEIJNEN, † P. J. M. ROTTIER, M. C. HORZINEK, AND W. J. M. SPAAN† \\ Department of Virology, Faculty of Veterinary Medicine, State University of Utrecht, \\ Yalelaan 1, P.O. Box 80.165, 3508 TD Utrecht, The Netherlands
}

Received 2 April 1992/Accepted 19 May 1992

\begin{abstract}
A new protein of feline infectious peritonitis coronavirus (FIPV) was discovered in lysates of ${ }^{35}$ S $]$ cysteinelabeled infected cells. Expression of open reading frame (ORF) $6 \mathrm{~b}$ of FIPV in recombinant vaccinia virus-infected cells was used to identify it as the $6 \mathrm{~b}$ protein. Further characterization revealed that it is a novel type of viral glycoprotein whose function is not clear. It is a soluble protein contained in microsomes; its slow export from the cell is caused by the presence of an endoplasmic reticulum (ER) retention signal at the $C$ terminus. This amino acid sequence, KTEL, closely resembles the consensus KDEL signal of soluble resident ER proteins. A mutant $6 \mathrm{~b}$ protein with the C-terminal sequence KTEV became resistant to digestion by endo- $\beta-N$-acetylglucosaminidase $H$ with a half-time that was reduced threefold. In contrast, a mutant with the sequence KDEL was completely retained in the ER. The FIPV $6 \mathrm{~b}$ protein is the first example of a viral protein with a functional KDEL-like ER retention signal.
\end{abstract}

The coronaviruses feline infectious peritonitis virus (FIPV) and transmissible gastroenteritis virus (TGEV) of swine are genetically closely related. However, FIPV contains a complete open reading frame (ORF), ORF 2, in the $3^{\prime}$ region of the genome which is absent from TGEV (3). ORF 2 is located $3^{\prime}$ of ORF 1 of mRNA 6 , potentially encodes a polypeptide of $24 \mathrm{kDa}$, and we suggested that it is produced from a bicistronic mRNA (3). According to the recently proposed nomenclature (2), ORF 1 and ORF 2 of mRNA 6 are now called ORF $6 a$ and ORF $6 b$, respectively. TGEV and FIPV have three structural proteins: the 200-kDa spike protein (S), the 46-kDa nucleocapsid protein (N), and the 26to $29-\mathrm{kDa}$ membrane protein $(\mathrm{M})$. The product of the ORF 6a counterpart of TGEV was recently identified in infected cells (8). FIPV ORF $6 \mathrm{~b}$ product contains a short $\mathrm{N}$-terminal hydrophobic region (3), which may function as a signal sequence, and one consensus $\mathrm{N}$ glycosylation site. ORF $6 \mathrm{~b}$ contains a single methionine codon, which might explain why it went unnoticed in previous metabolic labeling experiments performed with $\left[{ }^{35} S\right]$ methionine $(4,20)$. In this report, we show that the protein encoded by ORF $6 \mathrm{~b}$ is produced in FIPV-infected cells and that it is a novel type of viral glycoprotein.

\section{MATERIALS AND METHODS}

Cells and viruses. FIPV strain 79-1146 (12) was grown in Crandell feline kidney (CrFK) cells or in Felis catus whole fetus cells (fcwf-D, obtained from N. C. Pedersen). For vaccinia virus (strain WR, obtained from G. Wertz) infections, HeLa, human 143 thymidine kinase-negative (TK ${ }^{-}$), and rabbit kidney (RK-13) cells were used. Cells were maintained in Dulbecco modified Eagle medium (GIBCO Laboratories) containing $5 \%$ heat-inactivated fetal bovine serum.

RIPA. Lysates of FIPV- or vaccinia virus-infected cells were prepared after metabolic labeling with L-[ ${ }^{35}$ S $]$ methio-

\footnotetext{
* Corresponding author.

$\dagger$ Present address: Department of Virology, Faculty of Medicine, University of Leiden, Leiden, The Netherlands.
}

nine or $\mathrm{L}-\left[{ }^{35} \mathrm{~S}\right]$ cysteine (>1,000 Ci/mmol; Amersham Corp.). Radioimmunoprecipitation assays (RIPA) and endo- $\beta-N$ acetylglucosaminidase $\mathbf{H}$ (endo $\mathbf{H}$; Boehringer Mannheim Biochemicals) treatment were carried out as described previously (20). Neuraminidase (from Arthrobacter ureafaciens; Boehringer Mannheim Biochemicals) treatment was performed in $50 \mathrm{mM}$ sodium acetate buffer ( $\mathrm{pH} \mathrm{5)}$ for $16 \mathrm{~h}$ at $37^{\circ} \mathrm{C}$. Analysis by sodium dodecyl sulfate-polyacrylamide gel electrophoresis (SDS-PAGE) was done as described elsewhere (9).

Membrane fractionation. The membrane fractionation method was adapted from procedures described previously (7). Cells were suspended in $0.1 \times$ Tris-buffered saline (TBS; $25 \mathrm{mM}$ Tris hydrochloride [pH 7.5], $137 \mathrm{mM} \mathrm{NaCl}, 5 \mathrm{mM}$ $\left.\mathrm{KCl}, 0.7 \mathrm{mM} \mathrm{CaCl}_{2}, 0.5 \mathrm{mM} \mathrm{MgCl}_{2}, 0.6 \mathrm{mM} \mathrm{Na}_{2} \mathrm{HPO}_{4}\right)$ and disrupted by Dounce homogenization. Nuclei and cell debris were removed by low-speed centrifugation. One half of the lysate was diluted with an equal volume of $0.1 \times$ TBS; the other half was mixed with an equal volume of $200 \mathrm{mM}$ $\mathrm{Na}_{2} \mathrm{CO}_{3}$ (pH 11) and incubated for $10 \mathrm{~min}$ on ice. Microsomal membranes were pelleted by centrifugation in a Beckman TLA 100.2 rotor at $65,000 \mathrm{rpm}$ for $30 \mathrm{~min}$ at $4^{\circ} \mathrm{C}$. The supernatant fraction of the carbonate-treated material was neutralized with $\mathrm{HCl}$. The pellet and supernatant were analyzed by RIPA.

Cloning and expression of ORF 6b. Recombinant DNA techniques were performed essentially as described previously (11). A cDNA fragment extending from a SpeI site located 84 bp upstream of the initiation codon of ORF $6 \mathrm{~b}$ to a SalI site in the polylinker of CDNA clone E7 (3) was recloned in pTUG31 (21), a derivative of pET-3 (15) which contains bacteriophage $\mathrm{T} 7$ promoter and terminator transcription signals and which was used in combination with the T7 RNA polymerase-producing recombinant vaccinia virus vTF7-3 (6). The expression vector contains flanking vaccinia virus TK sequences which were used to prepare recombinant vaccinia virus vTF6b by procedures described elsewhere (10).

Site-directed mutagenesis. The C-terminal sequence of the $6 \mathrm{~b}$ protein was changed by site-directed mutagenesis. The synthetic oligonucleotides 5'-CGGGTTGCCTTATACCTC 
AG-3' and 5'-GCCTTATAACTCATCTTTATG-3' (Pharmacia LKB) are complementary to the C-terminal end of ORF $6 \mathrm{~b}$ and contain one and two mismatched nucleotides, respectively (underlined). The resulting coding sequences contain a GTA codon for valine instead of TTA for leucine or a GAT codon for aspartic acid instead of ACT for threonine. These oligonucleotides were used in the polymerase chain reaction (PCR) together with the universal M13 sequencing primer (Promega), with $10 \mathrm{ng}$ of M13 mp18 single-stranded DNA containing a 360-nucleotide XbaI-Pst I fragment of cDNA clone B12 (3) as a template and Taq DNA polymerase (Promega) as specified by the manufacturer. The PCR products of approximately $160 \mathrm{bp}$ were treated with Klenow DNA polymerase in the presence of deoxynucleoside triphosphates, digested with $K p n I$, purified from an agarose gel, and ligated with EcoRV- and KpnI-digested pBluescript $\mathrm{SK}^{-}$(Stratagene). The presence of the mutation and the integrity of the rest of the fragment were confirmed by sequence analysis. The inserts were cut with $X b a I$ and $B a m H I$ and ligated in a three-fragment ligation with an $X h o I-X b a I$ fragment of the remaining part of the $6 \mathrm{~b}$ gene and $X$ XoI- and BamHI-digested vector pTUG31 (21). The mutated constructs were designated pTF6bV and pTF6bD.

\section{RESULTS}

Identification of the FIPV $6 b$ protein. ORF $6 b$ of FIPV contains one methionine codon and seven cysteine codons. The electrophoretic patterns of immunoprecipitated lysates from $\left[{ }^{35} \mathrm{~S}\right]$ methionine- and $\left[{ }^{35} \mathrm{~S}\right]$ cysteine-labeled FIPV-infected cells were compared to identify ORF 6b-derived polypeptides. After $\left[{ }^{35}\right.$ S $]$ methionine labeling, the FIPV $\mathbf{M}$ protein appeared as a strong band of $29 \mathrm{kDa}$ and a minor band of $26 \mathrm{kDa}$ (Fig. 1A); these bands corresponded to the glycosylated and unglycosylated forms of the $M$ protein, respectively (20). In [ $\left.{ }^{35} \mathrm{~S}\right]$ cysteine-labeled immunoprecipitates, a double band of 26 to $26.5 \mathrm{kDa}$ was observed at the position of the unglycosylated $M$ protein band. When the samples were digested with endo $H$, which cleaves asparagine-linked high-mannose oligosaccharide side chains, a 24-kDa protein was detected exclusively after $\left[{ }^{35} \mathrm{~S}\right]$ cysteine labeling (Fig. 1A). These experiments demonstrate the presence of a hitherto unidentified glycoprotein in FIPV-infected cells which was readily immunoprecipitated by ascitic fluid from a field case of FIP. The differential labeling suggested that this novel protein is encoded by ORF 6b; its apparent molecular weight is in close agreement with the weight predicted from the amino acid sequence, and the shift after endo $\mathbf{H}$ treatment is consistent with the removal of one oligosaccharide side chain (13).

To test the hypothesis that ORF $6 \mathrm{~b}$ encodes this glycoprotein, the cloned $6 \mathrm{~b}$ gene was expressed in eukaryotic cells; it was recloned from cDNA clone E7 (3) into a bacteriophage T7 expression vector (Fig. 1B). The resulting construct, designated pTF6b, was used in the transient $\mathrm{T} 7$ expression system with recombinant vaccinia virus vTF7-3, which produces T7 RNA polymerase (6). The protein detected after immunoprecipitation comigrated with the $26.5-\mathrm{kDa}$ protein from FIPV-infected cells (Fig. 1A). Digestion with endo $\mathrm{H}$ yielded a protein which comigrated with the $24-\mathrm{kDa}$ protein mentioned above.

In order to determine whether the recombinant $6 \mathrm{~b}$ protein and the 26- to 26.5-kDa protein in FIPV-infected cells are the same, a competition RIPA was set up. Recombinant 6 b antigen was produced with recombinant vaccinia viruses vTF7-3 and vTF6b by the double-infection protocol (5).
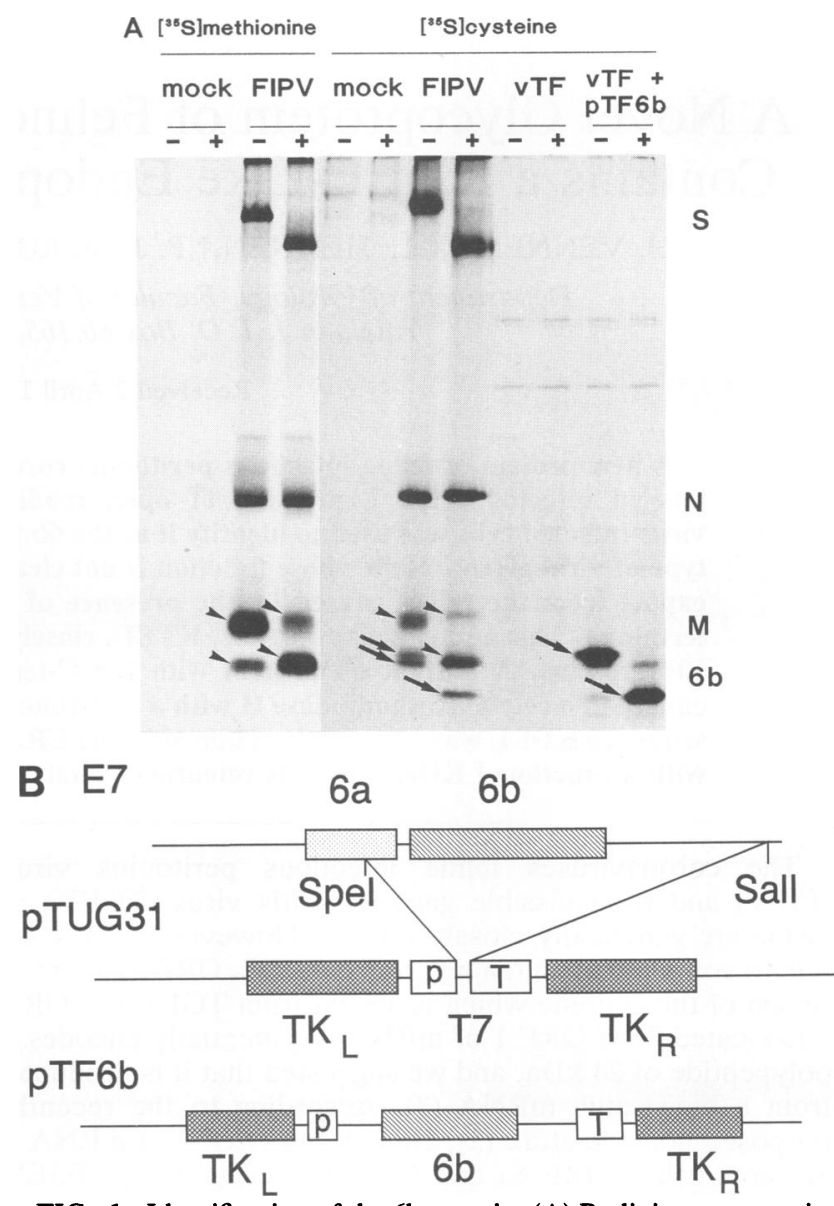

FIG. 1. Identification of the $6 \mathrm{~b}$ protein. (A) Radioimmunoprecipitation and SDS-PAGE analysis of lysates from infected cells. The RIPA was carried out with ascitic fluid containing anti-FIPV antibodies. Virus-specific proteins $S, N, M$, and $6 \mathrm{~b}$ are indicated. $M$ protein bands are indicated with arrowheads, and $6 \mathrm{~b}$ protein bands are indicated with arrows. Immunoprecipitates were split; one half $(+)$ was treated with endo $H$, and the other $(-)$ served as a control. FIPV-and mock-infected cells were labeled at $5 \mathrm{~h}$ postinfection with $\left[{ }^{35}\right.$ S $]$ methionine or $\left[{ }^{35}\right.$ S]cysteine. Recombinant vaccinia virus vTF73-infected cells and vTF7-3-infected, pTF6b-transfected cells (lanes vTF and vTF + pTF6b, respectively) were labeled for $30 \mathrm{~min}$ at 16 $h$ postinfection with $\left[{ }^{35} S\right]$ cysteine. (B) Cloning of ORF $6 \mathrm{~b}$ in a bacteriophage T7 expression vector. A SpeI-SalI fragment from cDNA clone E7 was recloned in pTUG31. The resulting expression construct, pTF6b, contains FIPV ORF $6 b$ flanked by a bacteriophage $T 7$ promoter $(p)$ and terminator $(T)$. Flanking vaccinia virus TK sequences were used for construction of recombinant vaccinia virus vTF6b.

Increasing amounts of lysate from unlabeled vTF7-3- and vTF6b-infected cells were added to constant amounts of

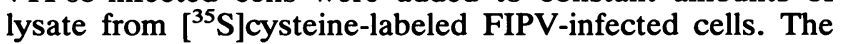
samples were then immunoprecipitated. Addition of unlabeled recombinant $6 \mathrm{~b}$ protein resulted in a decreased intensity of the 26- to $26.5-\mathrm{kDa}$ doublet but not of the FIPV M protein band (Fig. 2A) or of the bands of other FIPV proteins (19). In a control experiment, a similar competition RIPA was done with lysate from vTF7-3-infected cells transfected with pTFM, which contains the FIPV $M$ protein gene under the control of a T7 promoter (21). This resulted in a decrease in $\mathrm{M}$ protein band intensity only, demonstrating that both 


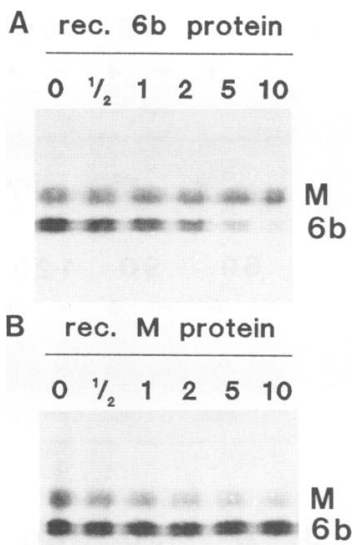

FIG. 2. Competition of immunoprecipitation with recombinant (rec.) $6 \mathrm{~b}$ and $\mathrm{M}$ proteins. Lysate from recombinant vaccinia virus vTF7-3-infected cells, superinfected with vTF6b (A) or transfected with pTFM (B), was added to samples of $\left[{ }^{35}\right.$ S $]$ cysteine-labeled lysate of FIPV-infected cells and processed for RIPA. The relative amount of unlabeled cell lysate is indicated above each lane. Virus-specific proteins ( $M$ and $6 b)$ are indicated. Only the relevant parts of the gels are shown.

bands of the doublet are unrelated to the $\mathrm{M}$ protein (Fig. 2B). A second control experiment was performed with lysate from vTF7-3-infected cells; at concentrations similar to those used for lysate from vTF6b- and vTF7-3-infected cells, band intensities were not diminished for any FIPV protein (19). These experiments demonstrate that ORF $6 \mathrm{~b}$ encodes the 26.5-kDa FIPV glycoprotein, which will be referred to as the $6 \mathrm{~b}$ protein from now on.

The $6 \mathrm{~b}$ protein is not an integral membrane protein. Apart from the $\mathrm{N}$-terminal signal sequence, no hydrophobic region which might serve as a membrane anchor was predicted from the $6 \mathrm{~b}$ amino acid sequence. Unless the signal sequence itself anchors the $6 \mathrm{~b}$ protein, it is not expected to be an integral membrane protein. Membrane fractionation was carried out to investigate this possibility. Crude fractionation of membranes by centrifugation resulted in complete recovery of the recombinant $6 b$ protein in the pellet (Fig. 3). Closed microsomal membrane vesicles were converted to open membrane sheets by carbonate treatment, leaving integral membrane proteins in the membrane and releasing soluble proteins and peripheral membrane proteins (7). After adjustment of the lysate to $100 \mathrm{mM} \mathrm{Na} \mathrm{CO}_{3}$ (pH 11), most of the $6 \mathrm{~b}$ protein was detected in the supernatant after centrifugation. The same analysis carried out for FIPV-infected cells resulted in the same fractionation pattern. The $S$ and $M$ proteins were convenient controls for integral membrane proteins, and both were recovered in the pellet fraction at both $\mathrm{pH} 11$ and 7.5. A large part of the $\mathrm{N}$ protein from FIPV-infected cells was found in the pellet at pH 7.5; this result probably reflects the association of the $\mathbf{N}$ protein with viral membrane proteins. Similar results were obtained recently for the $\mathbf{N}$ protein of infectious bronchitis virus (16). Our experiments show that the $6 \mathrm{~b}$ protein is not an integral part of microsomal membranes, but we cannot exclude the possibility that it is peripherally associated with membranes.

The $6 \mathrm{~b}$ protein is a secretory protein. Preliminary observations indicated that the $6 \mathrm{~b}$ protein is released into the medium of FIPV-infected cells. It remained to be determined

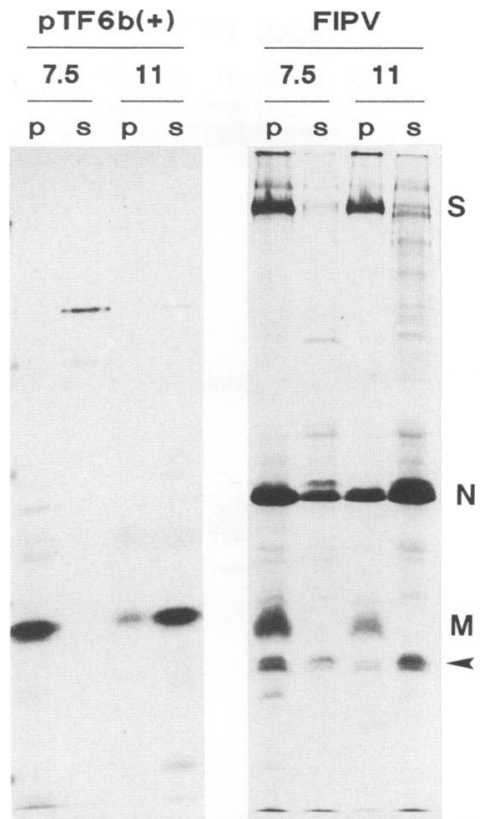

FIG. 3. Membrane fractionation of $6 \mathrm{~b}$ protein-producing cells. Cells transfected with pTF6b and infected with vTF7-3 [lanes pTF6b(+)] or infected with FIPV were labeled with [ ${ }^{35}$ S]cysteine. Membranes were pelleted after treatment at pH 7.5 or 11 as indicated. Membrane pellets and supernatants (lanes $p$ and $s$, respectively) were processed for RIPA. FIPV S, N, and M structural proteins are indicated. The gels contained different concentrations of acrylamide, which explains why the $6 \mathrm{~b}$ protein bands (indicated with arrowheads) did not comigrate.

whether the $6 \mathrm{~b}$ protein is a structural protein. It might be attached to virus particles as a peripheral membrane protein or by protein-protein interactions, which may have been disrupted in the carbonate extraction assay. Therefore, $\left[{ }^{35} \mathrm{~S}\right]$ cysteine-labeled virus was pelleted from the medium of infected cells by centrifugation; the pellet and supernatant fractions were processed for RIPA. The $6 \mathrm{~b}$ protein was found in the supernatant fraction but not in the pellet fraction, where the structural proteins accumulated (Fig. 4). The migration of $6 \mathrm{~b}$ was confirmed by coelectrophoresis of secreted recombinant $6 \mathrm{~b}$ protein. It was also not detectable in sucrose gradient-purified virus preparations by a Western blot (immunoblot) assay (19). Consequently, the $6 \mathrm{~b}$ protein is not stably associated with extracellular virus particles produced in tissue culture.

Posttranslational modifications of the $6 \mathrm{~b}$ protein. As demonstrated above, pulse-labeled $6 \mathrm{~b}$ protein was endo $\mathrm{H}$ sensitive (Fig. 1A); this sensitivity is indicative of $\mathbf{N}$ glycosylation. Inhibition of glycosylation with tunicamycin resulted in a $6 \mathrm{~b}$ protein band of $24 \mathrm{kDa}$ (19). After a 1-h labeling period, the $6 \mathrm{~b}$ protein appeared as a double band in FIPVinfected cells (Fig. 1A). By using shorter pulse-labeling times, we found that the upper band of the doublet is the precursor and that the lower band is a processing intermediate which appeared during the subsequent chase (Fig. 5A and B) or during long labeling periods. After longer chase times, the intermediate form was converted to the mature form. The precursor was fully susceptible to digestion by endo $\mathrm{H}$, whereas the intermediate and mature forms were resistant. The intermediate and mature forms were resolved best in the endo H-treated samples. Their subsequent appearance in these samples showed the precursor-product 


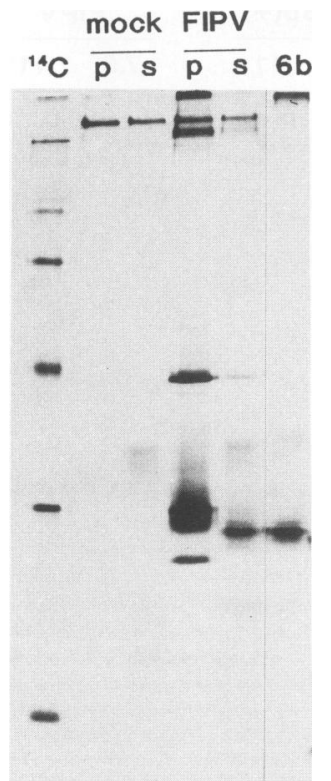

FIG. 4. Virus purification. Radioactively labeled virus was purified by centrifugation. The pellet and supernatant (lanes $p$ and $s$, respectively) of mock- and FIPV-infected cells were processed for RIPA. Secreted recombinant $6 \mathrm{~b}$ protein and ${ }^{14} \mathrm{C}$-labeled marker proteins were run in parallel for comparison (lanes $6 \mathrm{~b}$ and ${ }^{14} \mathrm{C}$, respectively).

relationship described above. The interpretation of the analysis of FIPV-infected cells was hampered by the presence of the $M$ protein in the same region of the gel. To reduce this problem, we made use of the hydrophobic nature of the $\mathbf{M}$ protein, which allowed extraction with Triton X-114 (17). Nevertheless, a small amount of $M$ protein remained in the samples (Fig. 5A). The mature form and the deglycosylated form of the $6 \mathrm{~b}$ protein could be unequivocally identified. The mature secreted $6 \mathrm{~b}$ protein had a higher apparent molecular weight than the intermediate form (Fig. 5C), which we assumed to be the result of terminal sialylation. In agreement with this assumption, digestion with neuraminidase increased its electrophoretic mobility (Fig. 5C). The analyses whose results are shown in Fig. 5A and B were carried out with lysates of cells combined with medium which were prepared by adding concentrated lysis buffer to the culture medium (20); this was done to avoid underestimation of product formation due to secretion into the chase medium. Acquisition of resistance to endo $\mathrm{H}$ digestion was estimated to be 80 to $90 \%$ complete after a 2-h chase period in FIPV-infected cells. Accurate measurements could not be made because of the interfering $M$ protein. In recombinant $6 \mathrm{~b}$ protein-producing cells, the process was slower; after a 3-h chase period, more than $50 \%$ of the $6 \mathrm{~b}$ protein was still endo $\mathrm{H}$ sensitive (see below).

Expression of C-terminally mutated $6 \mathrm{~b}$ protein genes. The $6 \mathrm{~b}$ protein C-terminal sequence, KTEL (3), is very similar to the KDEL signal of cellular resident endoplasmic reticulum (ER) proteins (14). We hypothesized that the KDEL-like sequence of the $6 \mathrm{~b}$ protein caused its partial retention in the $E R$. Therefore, we constructed a mutated version of the $6 \mathrm{~b}$ protein gene encoding the $\mathrm{C}$-terminal sequence KTEV. The alteration from leucine to valine merely removes a methylene group and preserves the hydrophobic nature. The same change has been demonstrated to abolish ER retention (1,
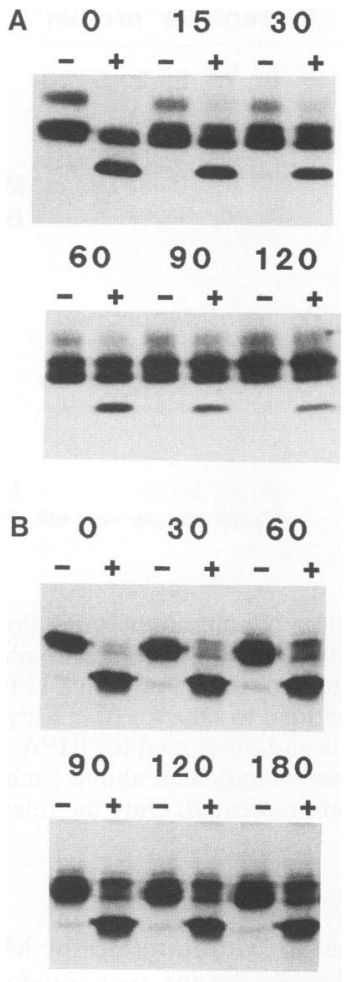

C cells medium

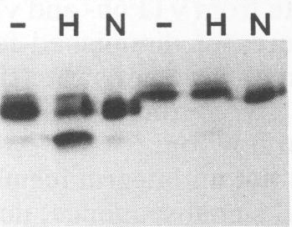

FIG. 5. Posttranslational modifications of the $6 \mathrm{~b}$ protein. Endo $H$ resistance acquisition by the FIPV (A) and recombinant (B) $6 \mathrm{~b}$ proteins is depicted. Cells were pulse-labeled and chased for the indicated periods (in minutes). RIPA and endo $\mathrm{H}$ analyses were carried out as described in the legend to Fig. 1. A small amount of $M$ protein remained in the FIPV samples. (C) Oligosaccharide side chains of intracellular and secreted recombinant $6 \mathrm{~b}$ protein. Recombinant vTF7-3- and vTF6b-infected cells were pulse-labeled and chased for $3 \mathrm{~h}$. Cells and medium were processed separately for RIPA. Samples were mock treated, endo $H$ treated, or neuraminidase treated, as indicated by,$- H$, and $N$, respectively. Only the relevant parts of the gels are shown.

22). The mutant construct, designated pTF6bV, was compared with the original construct in a pulse-chase experiment (Fig. 6). The protein encoded by pTF6bV, the $6 \mathrm{bV}$ protein, was secreted into the medium and became endo $\mathrm{H}$ resistant faster than the wild-type expression product. Quantitation of the results was done by liquid scintillation counting of bands excised from gels (Fig. 7). The half-times of endo $\mathrm{H}$ resistance acquisition were 3 and $1 \mathrm{~h}$ for the wild-type and the mutated $6 \mathrm{~b}$ protein, respectively. After a 3 -h chase period, $17 \%$ of the wild-type $6 \mathrm{~b}$ protein was secreted, compared with $50 \%$ of the $6 \mathrm{bV}$ protein. Next, we changed the C-terminal sequence to KDEL to determine whether this would confer complete ER retention. The resulting protein (the $6 \mathrm{bD}$ protein) was analyzed in a pulse-chase experiment (Fig. 6C). It was completely retained in the ER during a 3-h chase 
A

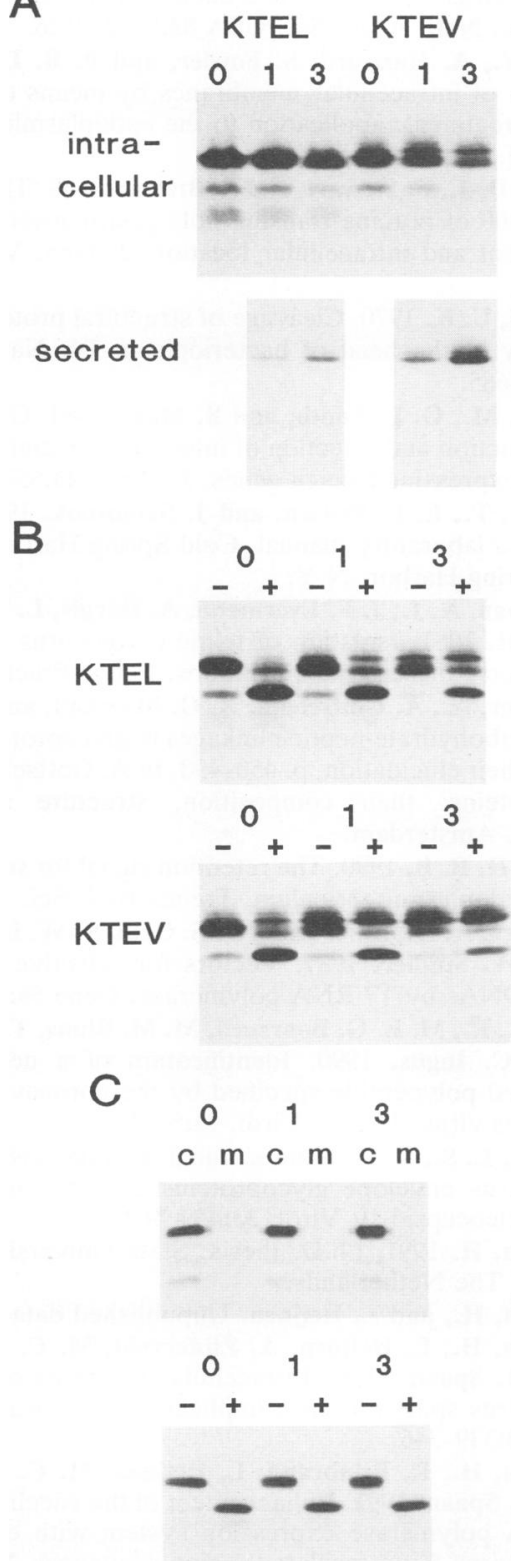

FIG. 6. Pulse-chase analysis of wild-type and mutated $6 \mathrm{~b}$ proteins. Cells infected with vTF7-3 were transfected with pTF6b or pTF6bV (indicated by KTEL and KTEV, respectively), pulselabeled for $1 \mathrm{~h}$, and analyzed immediately or after chase times of 1 and $3 \mathrm{~h}$, as indicated. Analysis was performed as described in the legend to Fig. 1. (A) Intracellular and secreted polypeptides were analyzed separately. (B) Lysates including the culture media were analyzed by endo $H$ digestion. (C) Similar experiments were performed with pTF6bD. Cells (lanes c) and medium (lanes m) were processed separately. Intracellular material was subsequently analyzed after treatment with endo $\mathrm{H}$ (lanes + ) or mock treatment (lanes -).

period; it could not be detected in the medium and remained entirely endo $\mathrm{H}$ sensitive. These experiments demonstrate that the original C-terminal sequence of the FIPV $6 \mathrm{~b}$ protein confers partial ER retention by the same mechanism used for cellular ER-resident proteins.

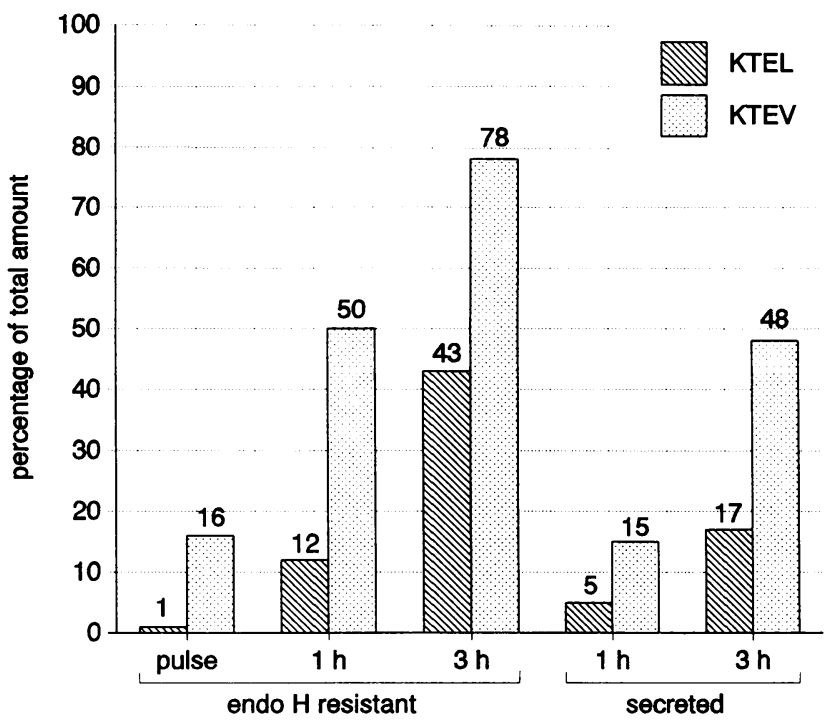

FIG. 7. Quantitation of wild-type and mutated $6 \mathrm{~b}$ protein transport. Immunoprecipitated $6 \mathrm{~b}$ proteins from at least two experiments were localized by fluorography; the bands were excised and quantitated by liquid scintillation counting. The percentage of endo $\mathrm{H}$-resistant material was calculated as the ratio of endo $\mathrm{H}$-sensitive counts to undigested counts, multiplied by 100 and subtracted from $100 \%$. The secreted fraction, expressed as a percentage, was calculated as 100 times the ratio of secreted counts to total counts.

\section{DISCUSSION}

In this article, we report the identification and characterization of a new virus-specific protein in FIPV-infected cells. A glycoprotein of $26.5 \mathrm{kDa}$ was detected in $\left[{ }^{35} \mathrm{~S}\right] \mathrm{cysteine}-$ labeled but not in $\left[{ }^{35} \mathrm{~S}\right]$ methionine-labeled cell lysates, which explains why it had not been observed before since previous labeling experiments were performed with $\left[{ }^{35}\right.$ S $]$ methionine $(4,20)$. The protein was identified by recombinant gene expression of the second ORF of mRNA 6 (3), currently designated ORF $6 \mathrm{~b}$. Further studies showed that the $6 \mathrm{~b}$ protein is a soluble protein contained in microsomes, that it is secreted from infected cells, and that it is not stably associated with virus particles in tissue culture medium.

Numerous ascitic fluid and serum specimens from naturally and experimentally infected cats immunoprecipitated the $6 \mathrm{~b}$ protein, whereas preinfection sera did not (19), which proves that it is also produced in vivo and confirms its virus specificity. In infected cats, secreted $6 \mathrm{~b}$ protein and antibodies against it may form immune complexes which play a role in the immunopathology of FIP. The function of the $6 \mathrm{~b}$ protein in the life cycle of FIPV is not clear. It is apparently nonessential for TGEV, from which it is completely absent; the closely related feline and canine enteric coronaviruses both produce $6 \mathrm{~b}$-like proteins and have $6 \mathrm{~b}$-like ORFs (18). The canine coronavirus ORF $6 \mathrm{~b}$ is colinear with that of FIPV and has $58 \%$ identity at the amino acid level. The feline enteric coronavirus ORF $6 \mathrm{~b}$ contains a deletion in the C-terminal half, reducing the colinear part to $60 \%$ of the FIPV ORF 6b.

Detailed analysis of its intracellular transport showed that the $6 \mathrm{~b}$ protein was released slowly from the ER, particularly in recombinant vaccinia virus-infected cells. The $6 \mathrm{~b}$ protein C-terminal sequence, KTEL, is almost identical to the KDEL signal of resident ER proteins. This signal or a closely related sequence at the $\mathrm{C}$ terminus of a protein with 
an N-terminal signal sequence is a strong indication that it is a resident luminal ER protein (14). Proteins with a KDEL signal are recognized by a receptor located in a compartment between the ER and the Golgi apparatus and recycled back to the ER. Site-directed mutagenesis of the signal to KTEV abolished retention; the half-life of endo $\mathrm{H}$ resistance acquisition of the $6 \mathrm{bV}$ protein was reduced threefold compared with that of the wild-type protein. The wild-type $6 \mathrm{~b}$ protein was not completely retained in the ER, while mutagenesis of its $C$ terminus to KDEL resulted in complete ER retention.

In comparison with transport of the recombinant expression product, $6 \mathrm{~b}$ protein transport was faster in FIPVinfected cells. Interference with the retrieval mechanism may be due to assembly of coronavirus particles in an intermediate compartment between the ER and the Golgi apparatus. Alternatively, the $6 \mathrm{~b}$ protein may bind transiently to immature virions or viral proteins in the ER and thereby escape from retrieval.

The FIPV $6 \mathrm{~b}$ protein is the first example of a viral protein with a functional KDEL-like ER retention signal.

\section{ACKNOWLEDGMENTS}

We thank Raoul de Groot for critical reading of the manuscript. B. Moss is gratefully acknowledged for providing the recombinant vaccinia virus $T 7$ expression system.

H.V. and L.H. were supported by a grant from Solvay-Duphar BV, Weesp, The Netherlands.

\section{REFERENCES}

1. Andres, D. A., J. D. Rhodes, R. L. Meisel, and J. E. Dixon. 1991. Characterization of the carboxyl-terminal sequences responsible for protein retention in the endoplasmic reticulum. J. Biol. Chem. 266:14277-14282.

2. Cavanagh, D., D. A. Brian, L. Enjuanes, K. V. Holmes, M. M. C. Lai, H. Laude, S. G. Siddell, W. Spaan, F. Taguchi, and P. J. Talbot. 1990. Recommendations of the Coronavirus Study Group for the nomenclature of the structural proteins, mRNAs, and genes of coronaviruses. Virology 176:306-307.

3. de Groot, R. J., A. C. Andeweg, M. C. Horzinek, and W. J. M. Spaan. 1988. Sequence analysis of the $3^{\prime}$ end of the feline coronavirus FIPV 79-1146 genome: comparison with the genome of porcine coronavirus TGEV reveals large insertions. Virology 167:370-376.

4. de Groot, R. J., R. J. ter Haar, M. C. Horzinek, and B. A. M. van der Zeijst. 1987. Intracellular RNAs of the feline infectious peritonitis coronavirus strain 79-1146. J. Gen. Virol. 68:9951002.

5. Fuerst, T. R., P. L. Earl, and B. Moss. 1987. Use of a hybrid vaccinia virus-T7 RNA polymerase system for expression of target genes. Mol. Cell. Biol. 7:2538-2544.

6. Fuerst, T. R., E. G. Niles, F. W. Studier, and B. Moss. 1986. Eukaryotic transient-expression system based on recombinant vaccinia virus that synthesizes bacteriophage T7 RNA polymerase. Proc. Natl. Acad. Sci. USA 83:8122-8126.

7. Fujiki, Y., A. Hubbard, S. Fowler, and P. B. Lazarow. 1982. Isolation of intracellular membranes by means of sodium carbonate treatment: application to the endoplasmic reticulum. J. Cell Biol. 93:97-102.

8. Garwes, D. J., F. Stewart, and P. Britton. 1989. The polypeptide of $M_{\mathrm{r}} 1400$ of porcine transmissible gastroenteritis virus: gene assignment and intracellular location. J. Gen. Virol. 70:24952499.

9. Laemmli, U. K. 1970. Cleavage of structural proteins during the assembly of the head of bacteriophage T4. Nature (London) 227:680-685.

10. Mackett, M., G. L. Smith, and B. Moss. 1984. General method for production and selection of infectious vaccinia virus recombinants expressing foreign genes. J. Virol. 49:857-864.

11. Maniatis, T., E. F. Fritsch, and J. Sambrook. 1982. Molecular cloning: a laboratory manual. Cold Spring Harbor Laboratory, Cold Spring Harbor, N.Y.

12. McKeirnan, A. J., J. F. Evermann, A. Hargis, L. M. Miller, and R. L. Ott. 1981. Isolation of feline coronavirus from two cats with diverse disease manifestations. Feline Pract. 11:16-20.

13. Neuberger, A., A. Gottschalk, R. O. Marshall, and R. G. Spiro. 1972. Carbohydrate-peptide linkages in glycoproteins and methods for their elucidation, p. 450-490. In A. Gottschalk (ed.), The glycoproteins: their composition, structure and function. Elsevier, Amsterdam.

14. Pelham, H. R. B. 1990 . The retention signal for soluble proteins of the endoplasmic reticulum. Trends Biol. Sci. 15:483-486.

15. Rosenberg, A. H., B. N. Lade, D.-S. Chui, S.-W. Lin, J. J. Dunn, and F. W. Studier. 1987. Vectors for selective expression of cloned DNAs by T7 RNA polymerase. Gene 56:125-135.

16. Smith, A. R., M. E. G. Boursnell, M. M. Binns, T. D. K. Brown, and S. C. Inglis. 1990. Identification of a new membraneassociated polypeptide specified by the coronavirus infectious bronchitis virus. J. Gen. Virol. 71:3-11.

17. Sturman, L. S., K. V. Holmes, and J. Behnke. 1980. Isolation of coronavirus envelope glycoproteins and interaction with the viral nucleocapsid. J. Virol. 33:449-462.

18. Vennema, H. 1991. Ph.D. thesis. State University of Utrecht, Utrecht, The Netherlands.

19. Vennema, H., and L. Heijnen. Unpublished data.

20. Vennema, H., L. Heijnen, A. Zijderveld, M. C. Horzinek, and W. J. M. Spaan. 1990. Intracellular transport of recombinant coronavirus spike proteins: implications for virus assembly. $\mathrm{J}$. Virol. 64:339-346.

21. Vennema, H., R. Rijnbrand, L. Heijnen, M. C. Horzinek, and W. J. M. Spaan. 1991. Enhancement of the vaccinia virus/phage T7 RNA polymerase expression system with encephalomyocarditis virus 5 '-untranslated region sequences. Gene 108:201210.

22. Zagouras, P., and J. K. Rose. 1989. Carboxy-terminal SEKDEL sequences retard but do not retain two secretory proteins in the endoplasmic reticulum. J. Cell Biol. 109:2633-2640. 